\section{Confusion over therapy}

\section{London}

CONFUSION generated by the halting of a trial of the antiviral compound acyclovir in HIV-infected patients has embarrassed the drug's manufacturers, the British company Wellcome - not to mention some sections of the British press.

On 29 December, the lead story in The Sunday Times proclaimed a major breakthrough in AIDS research, saying that a trial of the drug in 300 patients in Britain, Germany and Australia had revealed that the death rate in those receiving acyclovir and Wellcome's zidivudine (AZT), the main anti-retroviral agent used to combat HIV, was half that in the group receiving AZT alone.

The article reported Paul Griffiths, a virologist at the Royal Free Hospital in London involved in the trial, as saying that AIDS could become as treatable as diabetes by the end of the decade, and stated that the trial had been stopped on ethical grounds to allow patients in the control group access to acylcovir.

But a slightly different story has since emerged from Wellcome, the trial's sponsors. Paul Fidian, Wellcome's head of clinical virology, says that the finding of increased survival in patients given both drugs is not new, and that the trial reported in The Sunday Times was halted because preliminary data had revealed that orally-administered acyclovir does not seem to be effective in AIDS patients against cytomegalovirus (CMV), one of the herpes viruses.

The earlier trial showing an increase in survival after 'combined therapy' with AZT and acyclovir was also funded by Wellcome. Its results were presented with little fanfare — at the 1990 international AIDS conference in San Francisco, although a paper based around these results has not yet been published. Fidian says that the working hypothesis at the time was that acyclovir, a known anti- herpes agent, had improved survival by acting against $\mathrm{CMV}$, which was considered the herpes virus most likely to be fatal in AIDS patients. With this in mind, a second trial was designed to look more closely at the effects of acyclovir on CMV in HIVinfected patients whose CD4 cell counts had been reduced to less than 150 .

It is this trial which was halted by Wellcome shortly before Christmas, when Fidian and his colleagues found no indication from preliminary data that acyclovir was effective against CMV. Wellcome is now acutely embarrassed by the apparently contradictory stories.

Spokeswoman Rosemary Hennings says that the company is concerned about the effect the coverage will have on HIVinfected people, who "must be spinning at a rate of knots" in confusion. But one researcher involved in the trial criticizes Wellcome for announcing that the trial had been stopped just before the Christmas break, when few staff were available to field journalists' questions. Griffith, whose conversation with The Sunday Times sparked the controversy, was earlier this week unwell and not available for comment.

The trial's inconclusive result also leaves a perplexing question: what exactly is causing the increased survival reported in patients receiving both AZT and acyclovir? Fidian presumes that the effect is related to the action of acyclovir aginst one or more of the herpes viruses, although the precise mechanism is still a mystery.

Wellcome has also not ruled out using acyclovir-like compounds to combat CMV in AIDS patients. One possibility being investigated is to give an oral dose of a precursor compound that will be absorbed rapidly, and converted to acyclovir once in the body - giving a much higher blood concentration of acyclovir than is possible by giving the drug itself orally.

Peter Aldhous

\title{
Staff buyout for BTG?
}

\section{London}

THE management and staff of the British Technology Group (BTG), one of the world's principal technology transfer organization, are leading one of several bids to buy the company, when it is sold into the private sector later this year. Since legislation to privatize the state-owned company completed its passage through parliament last October, interested consortia have been submitting their bids to the accountants Price Waterhouse, who are handling the sale for the government.

Tony Chrismas, BTG's head of marketing, says that the consortium put together by management and staff comprises a number of investment trusts, foundations and pension funds (the government has said that no single shareholder should own more than 15 per cent of BTG's shares), but declines to name the parties involved. Price Waterhouse are similarly coy about the number of bids received, although Chrismas says "we think we know of two or three others". The accountants have yet to place a value on BTG, but the company is thought to be worth around $£ 40$ million. BTG hopes to begin detailed negotiations soon.

\section{Explosion kills one}

ONE researcher was killed and three injured last week in a chemical explosion at one of last US laboratories studying 'cold fusion'. Officials at the Stanford Research Institute (SRI), site of the blast, believe that a buildup of either deuterium or hydrogen in a sixinch tall reactor chamber caused the apparatus to explode, killing Andrew Riley, an Oxford University-trained researcher on contract with the Electric Power Research Institute (EPRI). Michael McKubre, who directed the SRI project, Stuart Smedely, another SRI researcher, and Steven Crouch-Baker of EPRI were injured by flying glass and metal. SRI checked and found no radiation after the blast, but has buried the remaining three reactor chambers until a investigation determines the exact cause of the explosion. Menlo Park, California, fire department authorities said that a pressure valve in one canister had stuck and that the researcher were attempting to manually release pressure when the container burst.

The SRI researchers were looking for excess heat production in an experimental reactor similar to that first used by Stanley Pons and Martin Fleischmann, the two University of Utah electrochemists who announced in 1989 that they had discovered a new energy-generating effect. The small reactors contain palladium electrodes in a deuterium bath, or a control set-up replacing the deuterium with regular water. After passing a current through the reactor, the Utah researchers claimed to detect an inexplicable excess of heat. For the past two years EPRI has been funding additional studies on the phenomena, trying to find an explanation for measurements of anomalous low-level excesses in both heat and nuclear product production. EPRI has spent $\$ 2$ million on the SRI project to date.

Christopher Anderson

\section{US ACADEMY OF SCIENCES}

\section{IOM gets top name}

Washington

KENNETH I. Shine, dean of the University of California, Los Angeles, School of Medicine, will become the next president of the Institute of Medicine (IOM). A heart specialist, Shine has been a long-time campaigner for hospital care reform. He will replace Samuel $O$. Thier, who left IOM last September to become president of Brandeis University. Shine will be the sixth president of the institute, which was created in 1970 as the medical policy arm of the National Academy of Sciences. Shine, a graduate of Harvard Medical School, will assume the Washington-based IOM presidency in July.

Christopher Anderson 